\title{
Smartphone' - A User-friendly Device to Deliver Affordable Healthcare - A Practical Paradigm
}

\author{
Talwar $\mathbf{Y K}^{1 *}$, Karthikeyan $\mathrm{S}^{2 *}$, Bindra $\mathrm{N}^{3}$ and Medhi $\mathrm{B}^{4}$ \\ ${ }^{1}$ Department of Hospital Administration, Post Graduate Institute Medical Education Research, Chandigarh, India \\ ${ }^{2}$ Department of Medical Records, Post Graduate Institute Medical Education Research, Chandigarh, India \\ ${ }^{3}$ Post Graduate Institute Medical Education Research, Chandigarh, India \\ ${ }^{4}$ Department of Pharmacology and Joint Medical Superintendent, Post Graduate Institute Medical Education Research, Chandigarh, India
}

\begin{abstract}
Introduction: The cutting edge Technology of the $21^{\text {st }}$ generation has proven to relinquish major positive enhancements and has left a huge impact in modern day medicine and health care. The Smartphone is one of the most commonly used devices in communication. It's rightly known as a "Handy-portal computer" which has made infinite contribution by its multitasked usages besides the specifically designed applications programmed to reach a quick and sound clinical decisions, these devices are also helping in health record maintenance, patient Management, education and training of healthcare professionals. This Journey of enhanced technology coverage with existing wisdom of the field can prove to be a major boon for mankind.
\end{abstract}

Objective: To highlight the enhanced contribution of the Smartphone in today's modern medicine by demonstrating the potential of technology and its future applications, be it for patient, implementation in healthcare and continuing medical education, for cross consultations, patient satisfaction, and removing communication barriers. Care has been taken to define and evaluate utility of evidence based technological advancements in the healthcare sector.

Methodology: In this study, a systematic review of literature was done via Preferred Reporting Items for Systematic Reviews and Meta-Analyses (PRISMA) for systematic review. Google scholar and MEDLINE were used to identify articles that discussed the utility design, development, evaluation, and utility of smartphone-based software for healthcare workers, professionals, medical or nursing students, or patients. A total of 59 articles discussing 88 applications were selected for this study from 2,934 articles initially obtained from the PubMed, scholar, and Medline searches.

Conclusions: The role of this technology in medicine and healthcare is seen to be promising and technologically exciting to use. We have tried to analyze and discussed many smartphone/App-based healthcare applications that are available in the literature. We also had found that most of these applications are grouped as per the target users namely the clinicians, administrators, medical and nursing students. Further as these applications were originally not intended to replace old desktop based applications, but to add to existing pool of technologies for better healthcare. The functional uses of these Apps are growing every day. The enhanced mobile connectivity and communication between health care professionals have contributed to ease and validity of medical care besides monitoring, access to evidence based medicine which includes better diagnosis guides, drug references, literature search, and continuing medical education materials at the point of care. Further as easy access is provided to all authorized personal of records, this has resulted in remote consultation and telemedicine. Further, Apps like Netra performing visual acuity test is also viable using a smartphone. The easy and widespread adoption of these mobile health technologies by the general masses further emphasize the opportunity of better mHealth and mobile telemedicine services through patient oriented applications.

Keywords: Smartphone; Healthcare; Mobile health; eHealth; Medical applications; Medical devices

\section{Introduction}

The new age device "Smartphone" is a link which connects communication system and endless cutting-edge technology driven apps in a pocket-carried device. The extreme consequence tool has been used to streamline the use of Smartphone-based healthcare technologies and applications, which is also commonly termed as e-health. This literature is a systematic reference, which gives emphasize on mobile Health. The present day heathcare infrastructure is totally mobile, which provides many numerous choices to patient. These choices are driven by their health care needs in various clinical locations and settings. Health information practices especially those including Appointments, Scheduling OPD visits, personal record keeping, Specialty clinic referrals, inpatient admissions, selection of specific consultations, privacy issues, Legal safeguards, Evidence based information, multiple grapples, Safely maintenances, Tracking of outpatient services, emergency counter needs, Operation theatres (OT) availability and judicious utilization, intensive care units
(ICUs) monitoring, reports from laboratories, digital imaging, sharing information etc can be streamlined with application of e-mobile health. HealthCare professionals nowadays need their patients Health information from point they are assigned to them till the final visit in electronic format and also prefer to keep it secure for future references in form of paperless

*Corresponding authors: Talwar YK, Department of Hospital Administration, PGIMER, Chandigarh, India, Tel: +917087009633, +919911246989; E-mail: drtalwaryatin@gmail.com

Karthikeyan S, Senior Medical Records Officer, PGIMER, Chandigarh, India, Tel: +917087009016, +919780558593; E-mail: karthikpgimer@gmail.com

Received May 11, 2016; Accepted June 06, 2016; Published June 13, 2016

Citation: Talwar YK, Karthikeyan S, Bindra N, Medhi B (2016) Smartphone' - A User-friendly Device to Deliver Affordable Healthcare - A Practical Paradigm. J Health Med Informat 7: 232. doi:10.4172/2157-7420.1000232

Copyright: @ 2016 Talwar YK, et al. This is an open-access article distributed under the terms of the Creative Commons Attribution License, which permits unrestricted use, distribution, and reproduction in any medium, provided the original author and source are credited. 
clinical practice. The strict working conditions in the healthcare industry and services requires extensive mobility of professional superadded with need for apt communication and collaboration amongst various strata's and levels, individuals including their colleagues and patients [1] which can be achieved and streamlined with the technological advanced e-health portals and mobile health apps.

Smartphone applications provides many benefits for patient, HealthCare professionals, and Healthcare education Provider's to deliver health information systemically, perhaps recently the most significant is accessing point-of-care tools in hand. This has lead to provide health care which is technologically sound as it offers quick clinical decision making and improved patient doctor relationship. Despite of the numerous benefits offered, better connectivity and standards and to validate the existing practices on mobile medical application, it is our duty to ensure the proper use of mobile application and establish it consistently. Streamlining of these e-health solutions with incorporation in medical application market, the quality and safety of the applications available presently will also increase tremendously. This will also take care of the health record maintenance, communications, services utilization, Information systems and time management; which will eventually help in improving management and monitoring of patients, will provide more efficient clinical decision-making capacity and later will contribute to medical training of trainees [2].

\section{Objective}

To highlight the enhanced contribution of the Smartphone in today`s modern medicine by demonstrating the potential of technology and its future applications, be it for patient, implementation in healthcare and continuing medical education, for cross consultations, patient satisfaction, and removing communication barriers. Care has been taken to define and evaluate utility of evidence based technological advancements in the healthcare sector.

A common acceptability has been through uses to the Physicians, Patients, and healthcare professionals who regularly use and carry a pocket sized Smartphone for various tasks, that help them to understand, treat and manage patients unmet needs easily, with use of applications, technology, both effectively and confidently. However, Smartphone are continuously evolving depending on user needs-be it calling, using Short message service or accessing emails to, to the real time mapping of nearest healthcare worker or setup in emergency, providing information about disease ailment or latest modalities and even sending data from a medical device over short distances.

\section{Method}

In this study, a systematic review of literature was done via Preferred Reporting Items for Systematic Reviews and Meta-Analyses (PRISMA) for systematic review. Google scholar and MEDLINE were used to identify articles that discussed the utility design, development, evaluation, and utility of Smartphone-based software for healthcare workers, professionals, medical or nursing students, or patients. A total of 59 articles discussing 88 applications were selected for this study from 2,934 articles initially obtained from the PubMed, Google scholar, Medline searches.

Key issues with recent use and modifications for Smartphone technology in the field of healthcare were evaluated and then compared vis a vis comparison between existing technologies with hand held potable device usage. Use of application in the cutting edge technology with minimal utilization of resources in healthcare setup also was indicated. Literature searches also identified the timeline of events that enabled Smartphone to determine the enhancement acceptance in healthcare, justifying the strengths and weakness.

The key findings have been discussed in a tabular form attached at the end of the study, notably the continent with internet usage and growth, uses of application by health care professionals, Applications and service categories (Tables 1-4).

\section{Discussion}

\section{Smartphone capabilities and its tools}

Comparing to previous generation phones, Smartphone have high quality capacity, are larger in size, and have higher resolution screens. The Smartphone of new generation incorporate various specifications like the tools of personal management, high definition quality cameras, also they can share information and record it. Smartphone has achieved pervasive presence in every body's life and society, as users find it easy to organize themselves. The Smartphone enabled culture of 'always being connected' to their peers and banks of information. The Smartphone also provide an opportunity of logging into the world of wide web knowledge from anywhere and at any time [3].

Smartphone's are quickly becoming a nearly ubiquitous technology. The first frontiers of e-health are APPs (applications) based software and detachable accessory additional hardware devices that can be plugged into a Smartphone. Many such compatible instruments like the e-weighing, e-blood pressure (BP) and pulseoximeters have already made their entry into many households. Health kiosks loaded with instructions can further empower patients to be play a more dominating role in their own health [4].

\section{Designing and developing an application in an easy mode and making its use comfortable}

The foremost basic in developing the application is towards the content themes and technical functionality. Initially in current scenario, a development platform is chosen with view of what end users want. Development of an application is done in two ways, either by the standard Java and Windows based platforms and by using mobile based app development tools. Java based tool is usually used by individuals while the latter is usually preferred by organizations, as in the later the dependency on programmers is reduced. The applications based on Smartphone's are different from other applications as one developed for Smartphones are based on the principle of easy navigation. This is also the reason why most applications are specific to Android, IOS users etc. Successful medical Smartphone application relays on the three accessibility, quality of the available content, usability, the need to match the consumers need and literacy level, security of the data and application and privacy. The application has three main innovative features [5]:

1. Privacy Rights, to ensure that no medical data is diluted or leaves the device;

\begin{tabular}{|c|c|c|c|}
\hline Continent & Total Population in \% & Users in \% & Growth in \% \\
\hline Asia & 60 & 48 & 8.8 \\
\hline Africa & 15 & 9.8 & 48.4 \\
\hline North America & 8 & 9.2 & 1.2 \\
\hline $\begin{array}{c}\text { South } \\
\text { America }\end{array}$ & 5.6 & 10.2 & 12.1 \\
\hline Europe & 11 & 17.8 & 3.1 \\
\hline Australia & 0.4 & 0.8 & 1.7 \\
\hline
\end{tabular}

Table 1: Continent with maximum internet users and growth [9]. 
Citation: Talwar YK, Karthikeyan S, Bindra N, Medhi B (2016) Smartphone' - A User-friendly Device to Deliver Affordable Healthcare - A Practical Paradigm. J Health Med Informat 7: 232. doi:10.4172/2157-7420.1000232

\section{Information system}

- Notes recording

- Conversation of notes in audio form

- Taking pictomyographs as documentary proof

- Hospital information services and imaging reporting in online format

- Using electronic document reader

- Cloud services databases and data bank

Time utilization

- Appointments/Registration

- Meetings/Conferences

- Duty roosters of doctors and emergency preparedness.

Health information Maintenance and Access

- Access of EMRs and EHRs

- E- image reporting

- E-drug prescribtion

- Auditing and E-billing
Communications and Consultation

- SMS /MMS / Calls (voice /video

- Video/Tele conferencing/ Teleevidencing

- Social networking and CME

Refering and medical knowledge banks

- Medical textbooks/references

- Medical articles

- Medical reviews

- Dedicated web based Literature search portals

- Drug reference literature

- Medical information and news

Clinical Decision-Making

- Clinical decision support systems(DSS)

- Latest accepted Protocols for treatement

- Disease causes and differential diagnosis
- Interpretation Laboratory test s

- Ordering Laboratory test

- Medical calculators and formulas

- Differential diagnosis aid

- Medical exams/Recuriting

Patient Monitoring system

- Vitals in ICU via smartphones

- Monitor patient location/mapping in cases of emergancy

- Patient rehabilitation after trauma and injury surgery

- Collect clinical data/information

- Monitor vital organ functions

Conitnued Medical Education and Handson

Training

- CME

- Knowledge apptitute and assessment exam

- Clinical meets and case study

- E-learning modules and training

- Surgical andanesthesia simulation modules with skill assessment

Table 2: Uses of applications by health care professionals [2].

\begin{tabular}{|c|c|}
\hline Useful Website/Application & Descriptions \\
\hline Forty six Application [46] & $\begin{array}{l}\text { Search platforms and Appointment Booking systems } \\
\text { Searching medications (Pharmacies), Doctors, Hospitals, Diagnostic } \\
\text { Centers and, Search by Name, Specialty and Location, } \\
\text { Booking of an online appointment } \\
\text { Alerts and Reminders } \\
\text { SMS (short message service) and reminders in form of emails. } \\
\text { Can be used for appointments, vaccination, medication reminders and } \\
\text { so on. } \\
\text { Detect various diseases and diagnosis } \\
\text { Evidence-based, high-impact practices for medical graduates. } \\
\text { Menstrual and Fertility tracker, pregnancy risk information guides. } \\
\text { Tracking Emergency Medical care and health services. Tracking GPS } \\
\text { location in times of emergency. } \\
\text { Treatment including medication, follow-up, investigations scheduler, } \\
\text { Personal health records maintaining.Heatlh planners. } \\
\text { Video consultations and tele-conferences, Remote health monitoring, } \\
\text { Training and Research }\end{array}$ \\
\hline Twenty one [21] & $\begin{array}{l}\text { Collect the data and storage in a data bank } \\
\text { The collected data is stored in a data bank and then is extracted in useful } \\
\text { formats. } \\
\text { images search. } \\
\text { Decision support system (DSS) for clinicians and professionals. } \\
\text { Developing mapping tools. } \\
\text { Deliver customers with services and latest methods of preventive } \\
\text { medicine and primordial prevention. }\end{array}$ \\
\hline
\end{tabular}

Table 3: M-health application available [16].

2. Enable auto application which self-updates that is the ability to update application content, without any restriction contained and

3. Simple, easy and automated transfer of relevant and specific data [6].

These apps later can be integrated with effective utilities like facial recognition, fingerprint detection, heart rate and eye sight detection, etc. The First user and adopter are clinicians who have already started to these devices and have developed confidence in there accuracy and efficacy. The reason for this overt acceptance is also due to the fact that, Smartphone-based e-devices are practically non-invasive and are user friendly with no learning curve. Secondly, the application of Smartphone e-devices also enables an auditory with/without visual representation of data that can be shared, enabling the patient to understand the exact pathology of the disease [7].

\section{Operating systems availability and its nature}

Every Smartphone is not based on the same operating system (OS). There are many operating systems, the usual common Operating Systems used such as: WindowMobiles ${ }^{\oplus}$, Apple Phones ${ }^{\oplus}$, Symbians ${ }^{\odot}$, GoogleAndroid, PalmT ${ }^{\odot}$, and Blackberry are the commonly preferred ones. The iPhone ${ }^{\oplus}$ OS till now had the highest market shared medical applications than any other system but $\mathrm{PalmT}^{\odot}$, WindowMobiles ${ }^{\odot}$, Blackberry $^{\odot}$ and GoogleAndroid are also rapidly surging ahead with their e-Health applications.

\section{Use of mobile applications in healthcare}

Healthcare is in full extent to potentially use the e-health mobile platforms to transform health information systems and clinical outcomes in the society. The indication and utilization of Smartphone for supporting e-health, mobile health and public health intervention 
Citation: Talwar YK, Karthikeyan S, Bindra N, Medhi B (2016) Smartphone' - A User-friendly Device to Deliver Affordable Healthcare - A Practical Paradigm. J Health Med Informat 7: 232. doi:10.4172/2157-7420.1000232

Page 4 of 7

\begin{tabular}{|c|c|c|c|c|c|c|}
\hline 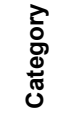 & Sub-category & User/Community & Involved Field & $\begin{array}{c}\text { Health Information } \\
\text { type }\end{array}$ & Service Platforms & Participators \\
\hline \multirow{5}{*}{ 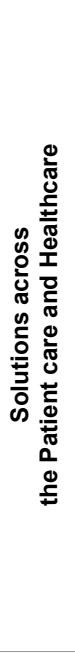 } & Wellbeing & Healthy Person & $\begin{array}{l}\text { - Morbid Obesity } \\
\text { - Better health } \\
\text { - Elderly management } \\
\text { - Child and post pregnancy } \\
\text { Care } \\
\text { - Tips- Pregnancy } \\
\text { - Anti-Smoking }\end{array}$ & $\begin{array}{c}\text { Voice } \\
\text { Interactive Services } \\
\text { (VIS) }\end{array}$ & $\begin{array}{c}\text { ISMS } \\
\text { IVR } \\
\text { App Device }\end{array}$ & $\begin{array}{l}\text { MO, } \\
\text { Device, } \\
\text { Vendor, } \\
\text { Software }\end{array}$ \\
\hline & Prevention of diseases & Patient & $\begin{array}{l}\text { - Infectious Diseases } \\
\text { - Drug Abuse Prevention } \\
\text { - Reproductive Health } \\
\text { - Child Health }\end{array}$ & Information & $\begin{array}{l}\text { SMS (including } \\
\text { USSD) } \\
\text { IVR }\end{array}$ & $\mathrm{MO}$ \\
\hline & Diagnosis of disease & Rural Area & $\begin{array}{l}\text { - Health e-call centers } \\
\text { - Help centers } \\
\text { - Tele-radio/medicine }\end{array}$ & e-Consultation & $\begin{array}{c}\text { Tele } \\
\text { Centers }\end{array}$ & $\begin{array}{c}\text { Service- Providers } \\
\text { MO }\end{array}$ \\
\hline & $\begin{array}{l}\text { Follow-up and } \\
\text { treatment }\end{array}$ & Specific person & - Adherence to treatment & $\begin{array}{c}\text { Reminders/ } \\
\text { Compliance Trackers }\end{array}$ & $\begin{array}{l}\text { SMS } \\
\text { IVR } \\
\text { Apps }\end{array}$ & $\begin{array}{c}\text { Content Developers } \\
\text { MO }\end{array}$ \\
\hline & Monitoring & $\begin{array}{c}\text { Chronic } \\
\text { Disease, especially high } \\
\text { risk and } \\
\text { Elderly }\end{array}$ & $\begin{array}{l}\text { - Chronic Disease } \\
\text { - Managing morbid } \\
\text { conditions } \\
\text { - Post emergency Care }\end{array}$ & $\begin{array}{l}\text { Tracking vitals. } \\
\text { e-Reporting and Alert } \\
\text { SMS }\end{array}$ & $\begin{array}{l}\text { Tele centers, } \\
\text { website based } \\
\text { Apps. }\end{array}$ & $\begin{array}{c}\text { MO } \\
\text { Device Vendors }\end{array}$ \\
\hline \multirow{4}{*}{ 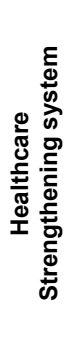 } & $\begin{array}{l}\text { Emergency } \\
\text { Response }\end{array}$ & Rapid response teams & $\begin{array}{l}\text { - Ambulance } \\
\text { - Other Misc Solutions }\end{array}$ & $\begin{array}{l}\text { Tracking vitals and } \\
\text { E-Consultation }\end{array}$ & $\begin{array}{l}\text { Device-linked } \\
\text { GPRS }\end{array}$ & $\begin{array}{c}\text { Device Vendors } \\
\text { MO }\end{array}$ \\
\hline & $\begin{array}{l}\text { Healthcare } \\
\text { Provider } \\
\text { Support }\end{array}$ & $\begin{array}{l}\text { Institutions } \\
\text { Doctors }\end{array}$ & $\begin{array}{l}\text { - Knowledge data base } \\
\text { - Decision Support } \\
\text { Systems(DSS) }\end{array}$ & Knowledge banks & $\begin{array}{l}\text { Apps and online } \\
\text { website based }\end{array}$ & $\begin{array}{l}\text { Software } \\
\text { MO }\end{array}$ \\
\hline & $\begin{array}{c}\text { Evaluation of healthcare } \\
\text { programmes }\end{array}$ & $\begin{array}{c}\text { Government, NGOs, } \\
\text { H-Workers }\end{array}$ & $\begin{array}{l}\text { - Health Surveillance \& } \\
\text { Surveys }\end{array}$ & $\begin{array}{c}\text { Collection of Data } \\
\text { with support in form of } \\
\text { reporting }\end{array}$ & $\begin{array}{c}\text { Apps } \\
\text { Website based }\end{array}$ & $\begin{array}{c}\text { MO } \\
\text { software }\end{array}$ \\
\hline & Hospital Administration & Individuals and Institutions & $\begin{array}{l}\text { - Reminder and patient } \\
\text { management }\end{array}$ & $\begin{array}{l}\text { Better patient } \\
\text { management }\end{array}$ & $\begin{array}{c}\text { Automated calls, } \\
\text { SMS }\end{array}$ & Software. MO \\
\hline
\end{tabular}

MO: Mobile Operator

Table 4: Mobile health service categories [8].

service, particularly in the data collection and analysis, supporting telemedicine, healthcare education and clinical practice in the community, and remote healthcare in developing nations are huge. The examples include their use in on-board digital diaries, off-site medical diagnosis and symptom research, short message service (SMS) text. GPS (Global Positioning System) location-enabled Smartphone's have shown to assist people with visual or hearing disabilities, chronic bedridden patients, disasters, emergency not to forget the role played in data collection and surveillance [4].

\section{Healthcare application's part in Electronic Medical Record 'EMR'}

Mobile Healthcare applications and device hardware is a continuous process of improving, developing new platform for upgrade and bring additional advancement, enhanced benefits and uses to clinical practice. The EMR databases over network can be applied in the mobile information, which is expected to combine and access larger databases, so that it can be enabled to be used in clinical decisionmaking. Thereafter, developing standards for mobile applications, which integrate seamlessly with HIS capabilities of EMRs and PACS (Picture Archiving and Communication System). These applications can lead to improved patient care with incorporated EMR [2].

\section{Terminologies in motion}

The terminology in the context of mobile technology is essential in improving the understanding between devices and applications. Mobile operating systems (mobile OSs), Smartphone's, personal digital assistants (PDAs), various healthcare applications and Mobile Internet Devices MIDs cloud computing has become a common feature among the newer generations of technology-driven healthcare providers [7-12].

\section{Managing and operating mobile devices in health care organization}

A simple five step approach can be adopted by an organization to manage/monitor mobile devices in a health care setting [8]: 'BYOD' Bring Your Own Device is a very effective strategy to manage the smart devices. This provides freedom and flexibility to the workers for using their own devices on organizational network, further also saves monetary spending on setting up an infrastructure. But, to implement BYOD many complexities are also seen as this leads to increased need of investment in Security networks, devices. Further specialists are needed to be hired for constant monitoring for possible security breaches/virus infection in the network.

Smartphone should be selected in a way as to store patients' health information securely and with ease, therefore they should be compatible with both organizations' internal electronic health record system and GPS 'Global positioning system'/CDMA 'Icode division Multiple Access' based internet connectivity.

- $\quad$ Risks detection and mitigation strategy needs to be devised and kept in place associated with the use of smart phones in transmitting the health information.

- Only authorized devices should be allowed in the organizations network. 
- Periodically there arises a need to conduct smart phone privacy and security awareness and ongoing training to workers.

- Newer digital devices have the potential to monitor, diagnose and prevent patient deterioration. Random blood sugar (RBS) meters are now leading the eHealth devices market, followed by heart monitoring devices.

\section{Smart applications and hand equipped devices are accurate in saving lives and time}

New digital devices have the potential to monitor and diagnose and prevent patient deterioration. Already OneTouch random glucose meters with ability to automatically and wirelessly transmit glucose readings to a Smartphone are being used (currently iOS only) [13].

\section{Mobile utility and monitoring by medical professional}

Radiologists are quickly adopting mobile apps to view and share images, collaborate with other physicians, and review files and databases. Applications like Mobile MIM that provides wireless and portable access to medical images and OsiriX, a full DICOM image viewer both make a big play on mobility in and away from the hospital workplace [14-20].

\section{Mobile device utility for "internal organ”}

Heart rate abnormalities, sounds and heart rate tracing especially in high risk patients have resulted in a major paradigm shift from hospital/clinic based monitoring to home based evaluation and monitoring. It's observed that the camera with its light-emitting diode (LED) source can measure heart rate accurately. Recently, work also has started on ECG recording with Smartphone. The use of Smartphone in echocardiography has been well documented [21-26].

\section{Smartphone application categories}

There are numerous Smartphone-based e-health applications presently available in market. In this analytical study, the various available applications were grouped into seven categories based on functional similarity of disease diagnosis, drug reference, medical calculators, literature search, clinical communication, HIS clients, and medical training. Whereas in some cases, when the applications which did not fall into any of these categories, they were classified under the "general healthcare applications". Finally, Application for Healthcare Professionals was drawn out category wise in numbers presently in use such as: Fifty seven applications for healthcare professionals, Twenty one disease diagnosis applications, Fifteen applications for patients, Six drug reference applications, Eight medical calculator applications, Six literature search applications, Three clinical communication applications, Four HIS client applications, Two medical training applications, Seven general healthcare applications, Twelve patients care applications, and Seven medical/nursing education applications [27-30]. However by referring the Google play store there were three hundred Applications available in the category of health care field.

\section{Extending mobile services to rural areas for assessing healthcare facilities}

Basic medical access in a rural setup has always been a challenge in every country. There is a huge disparity between urban and rural region nearly in every nation. In densely-populated regions more Health providers and specialists are likely to be located. In India, rural-dwellers gain access to medical care far from their home towns through video conferencing. Using broadband connections, doctors geographically remote from patients can examine them and diagnose particular problems. In countries where physicians are in short supply in rural areas, this enables those in under-served locales to get medical treatment [31].

\section{Stabilizing the use of smartphone in organizing primary health care services (PHC)}

The Smartphone based PHC services System can help to set a target of all members of the Family having a health profile or a portfolio as a valuable tool for maintenance of data which can be utilized for analysis and interpretation later [32-35]:

This can also lead to

(a) Better efficiency and efficient PHC services.

(b) Better quality of care with efficient referral and remote consultation setup.

(c) Better epidemiological surveillance, monitoring and control system.

(d) Pregnancy registration and other management enabled services.

(e) Forecasting for reduction mortality and morbidity rates.

\section{The significant role of smartphone in healthcare utilities}

The developed markets have encountered mobile penetration more than $100 \%$. Mobile penetrations in Africa, Asia, Latin countries have exceeded projected expectations. The increasing penetration of Smartphone's as well as the high speed internet networks have provided a significant boost which can be used for providing better healthcare services. Thus, there is always a feasibility of these e-health devices penetrating and being accepted widely. Mobile health - the use of mobile communication and devices for providing healthcare services or achieving health outcomes - stands at a significant inflection point [36].

\section{Applications of systems in India on mHealth}

Primary Health Care Services will ensure improved access to primary healthcare. This guardian function will lead less hospitalization, and also the chances of poor rural patient being subjected to unnecessary health interventions will reduce drastically. There are many Organizations that have projects for improving the functionality of ICT in Health care. UK-based Loughborough University professionals had been in joint venture with professionals in India to develop a single Smartphone healthcare standard. The standards are already been set, which have transformed paper records into e- records. Patient's vital sign recording, which include the typical electrocardiogram (ECG) cardiac signals are send to a hospital and can be accessed in any part of the world. Presently, this technology application is being used in ECG, $\mathrm{BP}$, puloximeters and random sugar levels [37-40].

\section{Limitations of the study in India}

Since the study is based in India, where there is a mixture of tribal, rural, semi urban and urban areas. There might be lower percentage of application use in some areas owing to poor connectivity and erratic electricity supply. Hence basic infrastructure setup with timely up gradation is also a factor which can play an important role and hence can be a limiting factor in the study [41-44].

Also the stratification of society in low middle and income groups overlapping with education status also can be a limitation to the study. As there has been no study done on difference in number of people using apps in lower socioeconomic and high socioeconomic strata, therefore we actually can't demarcate and predict the actual variability and difference in different socioeconomic index with respect to smartphone usage [45]. 
Since Indian mobile industry is very vast and variable with both high end and low ending types of devices (smartphones) available. Also variable internet packages are available as per the need of the user, availability of cell phone and internet has been not termed in limitation of the study, and however it can be a restriction in the study to some extent [46].

\section{Conclusion}

Smartphone's are efficient and handy devices and there utilization in a healthcare setting can be an asset, with due regards if some legal and ethical issues can be addressed in a timely manner, this technology can be included successfully in professional working setup. As this technology becomes more rampant, its integration into existing e-healthcare settings will be smoothened and in future appropriate advanced applications will be developed into a common utility. We also need to develop Policies and thereby guidelines for their approval and use, which later also need updating once the existing technology advances. The new users will also need to be trained in handling this adaptation. Hence the scope and benefits remain large. In Developing countries now the user's of Smartphone has grown drastically above the mark and internet use has provided easy access to services. The proper timely utilization of a Smartphone will eventually provide a better patient-doctor relationship with a healthier population. The health providers, developers, software engineers, and others will continue to adapt, adopt and contribute more for the Smartphone technology in this dynamic World [47].

The role of this technology in medicine and healthcare is seen to be promising and technologically exciting to use. We have tried to analyze and discussed many smartphone/App-based healthcare applications that are available in the literature. We also had found that most of these applications are grouped as per the target users namely the clinicians, administrators, medical and nursing students. Further as these applications were originally not intended to replace old desktop based applications, but to add to existing pool of technologies for better healthcare. The functional use of these Apps is growing every day. The enhanced mobile connectivity and communication between health care professionals have contributed to ease and validity of medical care besides monitoring, access to evidence based medicine which includes better diagnosis guides, drug references, literature search, and continuing medical education materials at the point of care. Further as easy access is provided to all authorized personal of records, this has resulted in remote consultation and telemedicine. Further, Apps like Netra performing visual acuity test is also viable using a smartphone. The easy and widespread adoption of these mobile health technologies by the general masses further emphasize the opportunity of better mHealth and mobile telemedicine services through patient oriented applications [48].

Most of the applications discussed in the study are standalone applications. There is an immense need for developing guidelines for standardizing smartphone-based healthcare applications so that the applications are used together seamlessly for specific purposes and are integrated with HISs such as EMR and patient monitoring systems to maximize the power of mobile applications. This will enable healthcare professionals to use the applications in a more meaningful way for better patient care.

The full potential of smartphones has yet to be exploited. We believe that this study provides a better understanding and greater insight into the effectiveness of the smartphone-based healthcare applications in improving patient care and reducing healthcare expenses.

\section{References}

1. Garritty CE, Emam K (2006) Who's using PDAs? Estimates of PDA use by health care providers: a systematic review of surveys. J Med Internet Res 8: e7.

2. Ammenwerth E, Buchauer A, Bludau B, Haux R (2000) Mobile information and communication tools in the hospital. International Journal of Medical Informatics 57: 21-40.

3. Banitsas KA, Georgiadis P, Tachakra S, Cavouras D (2004) Using handheld devices for real-time wireless teleconsultation. Conf Proc IEEE Eng Med Biol Soc 4: 3105-3108.

4. Bardram JE (2005) Activity-based computing: support for mobility and collaboration in ubiquitous computing. Personal and Ubiquitous Computing 9 : 312-322.

5. Bardram JE, Bossen C (2005) Mobility Work: The Spatial Dimension of Collaboration at a Hospital. Computer Supported Cooperative Work (CSCW) 14: $131-160$.

6. Burdette SD, Herchline TE, Oehler R (2008) Surfing the web: practicing medicine in a technological age: using smartphones in clinical practice. Clin Infect Dis 47: 117-122.

7. Wu RC, Morra D, Quan S, Lai S, Zanjani S, et al. (2010) The use of smartphones for clinical communication on internal medicine wards. J Hosp Med 5: 553-559.

8. Junglas I, Abraham C, Ives B (2009) Mobile technology at the frontlines of patient care: Understanding fit and human drives in utilization decisions and performance. Decis Support Syst 46: 634-647.

9. Sherry J, Salvador T (2001) Running and grimacing: the struggle for balance in mobile work. Wireless world: social and interactional aspects of the mobile age. Edited by: Brown B, Green N, Harper R, New York, NY: Springer-Verlag, pp: 108-120.

10. Lindquist AM, Johansson PE, Petersson GI, Saveman BI, Nilsson GC (2008) The use of the Personal Digital Assistant (PDA) among personnel and students in health care: a review. J Med Internet Res 10: e31.

11. Phua J, Lim TK (2008) How residents and interns utilise and perceive the personal digital assistant and UpToDate. BMC Med Educ 8: 39

12. Serdar MA, Turan M, Cihan M (2008) Rapid access to information resources in clinical biochemistry: medical applications of Personal Digital Assistants (PDA) Clinical and Experimental Medicine 8: 117-122.

13. Gamble K (2009) Beyond phones. With the proper infrastructure, smartphones can help improve clinician satisfaction and increase EMR use. Healthcare informatics: the business magazine for information and communication systems. Europe PMC 26: 23-24.

14. M B (2010) Proceedings of Umeå's 14th Student Conference in Computing Science. Opportunities and Challenges when Applying Mobile Technology in Health Care Umeå, SWEDEN: Umeå University, pp: 1-12.

15. Choudhri AF, Radvany MG (2011) Initial experience with a handheld device digital imaging and communications in medicine viewer: OsiriX mobile on the iPhone. J Digit Imaging 24: 184-189.

16. Millán M, Muñoz A, de la Villa M, Maña MJ (2010) A Biomedical Information Retrieval System based on Clustering for Mobile Devices. Natural Language Processing, pp: 255-258

17. Zolfo M, Iglesias D, Kiyan C, Echevarria J, Fucay L, et al. (2010) Mobile learning for HIVIAIDS healthcare worker training in resource-limited settings. AIDS Res Ther 7: 35

18. Lippi G, Plebani M (2011) Laboratory applications for smartphones: risk or opportunity? Clin Biochem 44: 273-274.

19. Eysenbach G (2000) Consumer health informatics. BMJ 320: 1713-1716.

20. Marshall A, Medvedev O, Antonov A (2008) Use of a smartphone for improved self-management of pulmonary rehabilitation. Int J Telemed Appl.

21. Hong S, Kim S, Kim J, Lim D, Jung S, et al. (2009) 31st Annual Internationa Conference of the IEEE EMBS. Portable emergency telemedicine system ove wireless broadband and $3 \mathrm{G}$ networks. Minneapolis, Minnesota, USA: IEEE, pp: 1250-1253

22. Krishna S, Boren SA, Balas EA (2009) Healthcare via cell phones: a systematic review. Telemed J E Health 15: 231-240. 
Citation: Talwar YK, Karthikeyan S, Bindra N, Medhi B (2016) Smartphone' - A User-friendly Device to Deliver Affordable Healthcare - A Practical Paradigm. J Health Med Informat 7: 232. doi:10.4172/2157-7420.1000232

23. Charpentier G, Benhamou PY, Dardari D, Clergeot A, Franc S, et al. (2011) The Diabeo Software Enabling Individualized Insulin Dose Adjustments Combined With Telemedicine Support Improves HbA1c in Poorly Controlled Type 1 Diabetic Patients: A 6-month, randomized, open-label, parallel-group, multicenter trial (TeleDiab 1 Study). Diabetes Care 34: 533-539.

24. Demaerschalk BM (2011) Telemedicine or Telephone Consultation in Patients with Acute Stroke. Current Neurology and Neuroscience Reports 11: 42-51.

25. Liang X, Wang Q, Yang X, Cao J, Chen J, et al. (2011) Effect of mobile phone intervention for diabetes on glycaemic control: a meta-analysis. Diabet Med 28: $455-463$

26. Worringham C, Rojek A, Stewart I (2011) Development and feasibility of a smartphone, ECG and GPS based system for remotely monitoring exercise in cardiac rehabilitation. PLoS One 6: e14669.

27. Brock TP, Smith SR (2007) Using digital videos displayed on personal digita assistants (PDAs) to enhance patient education in clinical settings. International Journal of Medical Informatics 76: 829-835.

28. Cole-Lewis $\mathrm{H}$, Kershaw $\mathrm{T}$ (2010) Text messaging as a tool for behavior change in disease prevention and management. Epidemiol Rev 32: 56-69.

29. Moher D, Liberati A, Tetzlaff J, Altman DG (2009) Preferred reporting items for systematic reviews and meta-analyses: the PRISMA statement. Ann Intern Med 151: 264-269.

30. Oehler RL, Smith K, Toney JF (2010) Infectious diseases resources for the iPhone. Clin Infect Dis 50: 1268-1274.

31. Richardson WS, Burdette SD (2003) Practice corner: taking evidence in hand. Evidence Based Medicine 8: 4-10.

32. Pope L, Silva P, Almeyda R (2010) i-Phone applications for the modern day otolaryngologist. Clin Otolaryngol 35: 350-354.

33. Busis N (2010) Mobile phones to improve the practice of neurology. Neurol Clin 28: 395-410.

34. Stroud SD, Smith CA, Erkel EA (2009) Personal digital assistant use by nurse practitioners: a descriptive study. Journal of the American Academy of Nurse Practitioners 21: 31-38.

35. Schreiber WE, Busser JR, Huebsch S (2008) A portable laboratory test reference for handheld computers: evaluation on an internal medicine clerkship. Am J Clin Pathol 129: 439-444.
36. León SA, Fontelo P, Green L, Ackerman M, Liu F (2007) Evidence-based medicine among internal medicine residents in a community hospital program using smart phones. BMC Medical Informatics and Decision Making 7: 5-10.

37. Burdette SD, Herchline TE, Richardson WS (2004) Killing bugs at the bedside a prospective hospital survey of how frequently personal digital assistants provide expert recommendations in the treatment of infectious diseases. Ann Clin Microbiol Antimicrob 3: 22

38. Miller SM, Beattie MM, Butt AA (2003) Personal digital assistant infectious diseases applications for health care professionals. Clinical infectious diseases: an official publication of the Infectious Diseases Society of America 36: 1018-1029.

39. Joundi RA, Brittain JS, Jenkinson N, Green AL, Aziz T (2011) Rapid tremor frequency assessment with the iPhone accelerometer. Parkinsonism \& Related Disorders 17: 288-290.

40. Mezzana P, Scarinci F, Marabottini N (2011) Augmented reality in oculoplastic surgery: first iPhone application. Plast Reconstr Surg 127: 57e-58e.

41. Lapinsky SE (2007) Mobile computing in critical care. Journal of Critical Care 22: $41-44$

42. Dala-Ali BM, Lloyd MA, Al-Abed Y (2011) The uses of the iPhone for surgeons Surgeon 9: 44-48.

43. Johansson PE, Petersson GI, Nilsson GC (2010) Personal digital assistant with a barcode reader--a medical decision support system for nurses in home care. Int J Med Inform 79: 232-242.

44. Chatterley T, Chojecki D (2010) Personal digital assistant usage among undergraduate medical students: exploring trends, barriers, and the advent of smartphones. Journal of the Medical Library Association 98: 157-160.

45. Baumgart DC (2005) Personal digital assistants in health care: experienced clinicians in the palm of your hand? Lancet 366: 1210-1222.

46. Hunter T, Hardwicke J (2010) The smart phone: An indispensable tool for the plastic surgeon? Journal of Plastic, Reconstructive \& Aesthetic Surgery 63 e426-e427.

47. Alexander G, Hauser S, Steely K, Ford G, Demner-Fushman D (2004) A usability study of the PubMed on Tap user interface for PDAs. Stud Health Technol Inform 107: 1411-1415.

48. Hauser SE, Demner-Fushman D, Ford G, Thoma GR (2004) PubMed on Tap: discovering design principles for online information delivery to handheld computers. Studies in Health Technology and Informatics 107: 1430-1433. 